\title{
Mcl-1 stabilization confers resistance to taxol in human gastric cancer
}

\author{
Wu Shuang ${ }^{1, *}$, Lili Hou ${ }^{2, *}$, Yan Zhu ${ }^{3, *}$, Qun Li $^{1}$ and Wanglai Hu ${ }^{1}$ \\ ${ }^{1}$ Department of Immunology, Anhui Medical University, Hefei, China \\ ${ }^{2}$ Department of Clinical Nutriology, The First Affiliated Hospital of Anhui Medical University, Hefei, China \\ ${ }^{3}$ Department of Anesthesiology, The First Affiliated Hospital of Anhui Medical University, Hefei, China \\ *These authors have contributed equally to this work \\ Correspondence to: Wanglai Hu, email: wanglaihu@ahmu.edu.cn \\ Keywords: Mcl-1, PI3K/Akt, Taxol-resistance \\ Received: March 08, $2017 \quad$ Accepted: July 26, $2017 \quad$ Published: August 12, 2017 \\ Copyright: Shuang et al. This is an open-access article distributed under the terms of the Creative Commons Attribution License \\ 3.0 (CC BY 3.0), which permits unrestricted use, distribution, and reproduction in any medium, provided the original author and \\ source are credited.
}

\section{ABSTRACT}

Taxol has been extensively used as an antineoplastic drug to treat human gastric cancer. However, the acquired drug resistance invariably develops and greatly limits the therapeutic efficacy of Taxol. Identification of the underlying resistance mechanisms may inform the development of new therapies of gastric cancers to Taxol treatment. Here we report that upregulation of Mcl-1 (Myeloid cell leukemia-1) confers acquired resistance to Taxol in human gastric cancer. Mcl-1 is shown to be stabilized in Taxol -resistant gastric cancer cells because of the hyper-activation of the PI3K/Akt signaling pathway. The increased Mcl-1 prevents of the permeabilization of the outer mitochondrial membrane, thereby blocking the Taxol-induced apoptosis. Furthermore, inhibition of Mcl-1 or PI3K/Akt pathway significantly reversed the resistant phenotype of Taxol-resistant human gastric cancer cells. Taken together, our findings broaden the view of PI3K/Akt pathway as an important regulator in Taxol acquired resistance, and implicate $\mathrm{Mcl}-1$ as a specific therapeutic target for the treatment of Taxol-resistant human gastric cancer.

\section{INTRODUCTION}

Gastric cancer, one of the most common malignant tumors in the world, is the third most common cause of cancer mortality worldwide. Patients with gastric cancer are often diagnosed in advanced stages and therefore associated with poor prognosis [1].

The mainstream treatment for the patients with gastric cancer at advanced stage or relapse after surgery is chemotherapy [2].

Taxol is a natural product with potent anti-tumor effect that widely used in gastric cancer therapy. Taxol against gastric cancer mainly through promoting the polymerization of tubulin, and thereby disrupting the normal microtubule dynamics required for cell division and interphase processes. Although the anti-tumor effects of Taxol are commonly exhibited through its induction of mitotic catastrophe, there is compelling evidence suggesting that Taxol acts through different apoptotic mechanisms, such as down-regulates Bcl-2 and Bcl$\mathrm{xL}$ expression, and causes cell cycle arrest at the G2/M phase $[3,4]$. Nevertheless, the response to Taxol therapy is limited by acquired resistance.

Over the past years, some mechanisms of acquired resistance to Taxol have been elucidated. Mutations of tubulin were reported to be a strong determinant of Taxol resistance in non-small cell lung cancer [5,6]. Alterations in tubulin expression and polymerization dynamics are considered to be related to resistance to Taxol [7]. In addition, membrane phosphoglycoproteins that function as drug-efflux pumps were shown to have an important role in the development of resistance to Taxol [8]. Recently, emerging evidence suggests that several pathways, such as the mitochondrial pathway and the EGFR pathway 
were involved in Taxol resistance. Critical genes in regulation of these pathways have been discovered, e.g., Bcl-2, Bcl-xl and p53. Regulation of these apoptosisrelated genes also been involved in the regulation of Taxol acquired resistance [9-13]. Given the diversity and complexity of these identified mechanisms associated with Taxol acquired resistance, fully defining the underlying mechanisms of resistance is still a priority to develop rational strategies to improve the therapeutic efficacy of human gastric cancer cells to Taxol.

To identify novel mechanism(s) of acquired resistance to Taxol, we generated Taxol-resistant cell line by chronic exposure of a human gastric cancer cell line to Taxol. Here we report Mcl-1 as a novel Taxol resistanceassociated gene. Mcl-1 is highly upregulated in Taxolresistant human gastric cancer cells and the up-regulation of Mcl-1 confers the resistance of gastric cancer cells to Taxol. The Mcl-1 is stabilized by hyper-activation of the $\mathrm{PI} 3 \mathrm{~K} / \mathrm{Akt}$ signaling pathway. Increased Mcl-1 is shown to confer Taxol acquired resistance by inhibiting induction of cytochrome $\mathrm{C}$ release. We also show that inhibition of Mcl-1 indeed renders gastric cancer cells sensitive to Taxol-induced apoptosis. Collectively, these data suggest that Mcl-1 stabilization response to $\mathrm{PI} 3 \mathrm{~K} / \mathrm{Ak}$ pathway plays an important role in the development of Taxol resistance in human gastric cancer cells.

\section{RESULTS}

\section{Mcl-1 upregulation confers the resistance of gastric cancer cells to Taxol}

The development of acquired resistance greatly dropped the efficacy of Taxol in human cancer treatment. To investigate the molecular mechanism(s) responsible for the acquired resistance of gastric cancers to Taxol, we generated a Taxol-resistant cell line by chronic exposure of gastric cancer cell line MGC-803 to $50 \mathrm{nM}$ Taxol for four weeks. This Taxol-resistant cell line was referred to as MGC-803R hereafter. The resistance of MGC$803 \mathrm{R}$ was become stable after approximately 6 months of continuous selection and was confirmed by MTT and long-term colony formation assays (Figure 1A and 1B). In order to identify novel gene candidates involving in the resistance to Taxol, we compared the expression level of a panel of genes in MGC-803 and MGC-803R by western blot analysis and real-time RT-PCR analysis (data not shown). Through this analysis, we found the anti-apoptotic protein Mcl-1 was noticeably upregulated in MGC-803R than MGC-803 (Figure 1C), whereas Bcl-2 and Bcl-xl, the other anti-apoptotic members of the Bcl-2 family, showed little, if any, responses to Taxol acquired resistance (Supplementary Figure 2).

We next determined whether increased expression of Mcl-1 confers acquired Taxol- resistant phenotype of MGC-803R. We first knocked down Mcl-1 in these cells, compared with the control, Mcl-1 knockdown MGC-803R showed a dramatic decrease in cell viability in response to Taxol treatment (Figure 1D). Furthermore, this Taxolinduced cell viability inhibition of Mcl-1 knockdown MGC-803R cells was reversed by ectopic expression of Mcl-1 (Figure 1E). We next evaluated this effect of Mcl1 on Taxol-induced inhibition on cell viability in MGC803 cells. As shown in Figure 1F, the inhibitory effect was greatly reversed by ectopic expression of Mcl-1 in MGC803 cells.

To further confirm the effect of Mcl-1 upregulation in acquired Taxol resistance in vivo, we performed a xenograft mouse model. MGC-803R cells with and without stable knockdown of Mcl-1 were individually injected subcutaneously into the right flank of nude mice, and mice were treated with Taxol $(20 \mathrm{mg} / \mathrm{kg})$ through intraperitoneal injection. As shown in Supplementary Figure 4A, MGC-803R xenografts were largely abolished by Mcl-1 knockdown. This was also confirmed by a significant decrease in xenograft weights (Supplementary Figure 4B). Taken together, these results strongly suggest the critical role of $\mathrm{Mcl}-1$ in the acquired resistance to Taxol in human gastric cancer cells.

\section{Mcl-1 stabilization is regulated by the PI3K/Akt pathway}

We next investigate the molecular mechanism whereby Mcl-1 was upregulated in MGC-803R cells. Mcl1 mRNA levels were not affected in MGC-803 and MGC803R cells, as determined by real-time RT-PCR analysis (Figure 2A). However, Mcl-1 half-life was increased in MGC-803R cells (Figure 2B). These data suggest that Mcl-1 was upregulated in MGC-803R cells due to the increased protein stability.

The PI3K/Akt pathway has previously been demonstrated to increase Mcl-1 stability by inhibiting the phosphorylation of Mcl-1 [14]. Intriguingly, MGC803R cells were shown to exhibit higher levels of phosphorylated Akt (S473)(p-Akt) than MGC-803 cells, but the phosphorylated ERK(p-ERK) showed similar levels in these two cells (Figure 2C), indicating that $\mathrm{PI} 3 \mathrm{~K} / \mathrm{Akt}$ pathway is specifically enhanced in Taxol-resistant gastric cancer cells. Previous studies have shown that the PI3K/Akt pathway could stabilize Mcl-1 by promoting GSK-3 $\alpha$ phosphorylation at serine 21 and GSK-3 $\beta$ phosphorylation at serine 9 [15]. To determine the specific role of the PI3K/Akt pathway in mediating $\mathrm{Mcl}-1$ upregulation, phosphorylation of both GSK $3 \alpha$ and GSK-3 $\beta$ were analyzed in MGC-803 and MGC-803R cells. As shown in Supplementary Figure 2, MGC-803R cells indeed exhibit higher levels of phosphorylated GSK $3 \alpha(\operatorname{Ser} 21)$ and phosphorylated GSK3 $\beta$ (Ser9) than MGC-803 cells, although the total GSK $3 \alpha$ and GSK $3 \beta$ protein showed similar levels in these two cells. 
A

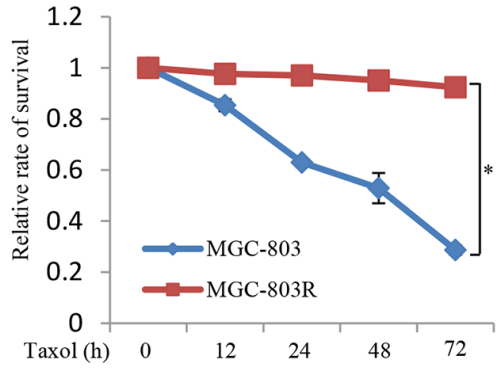

B

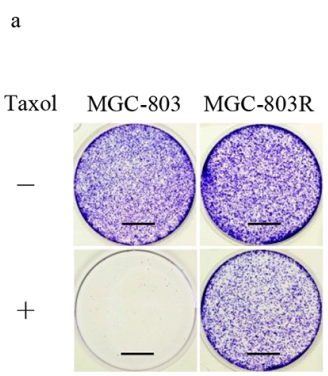

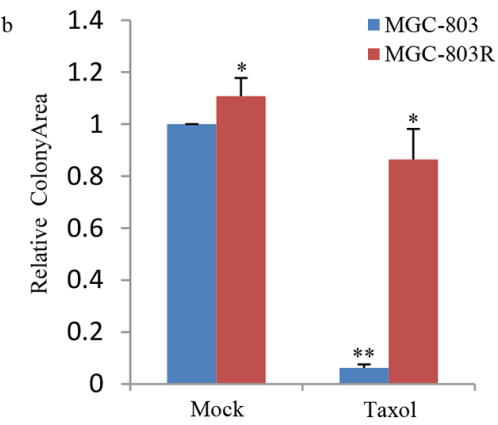

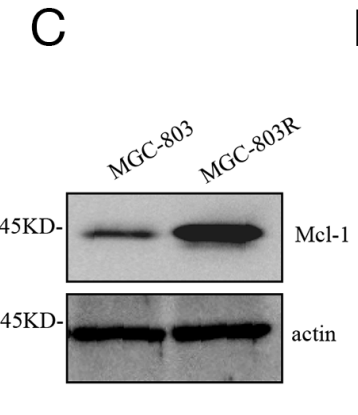

$\mathrm{D}$
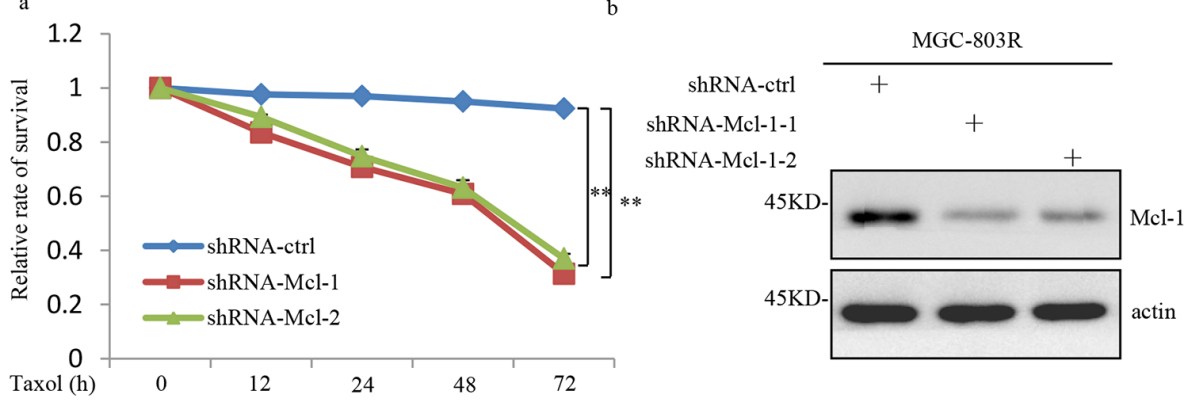

E

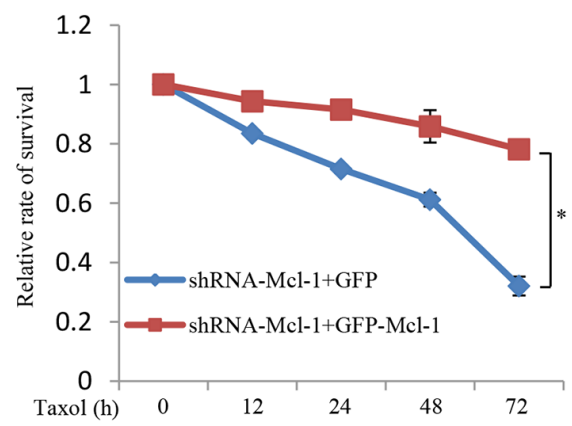

$\mathrm{b}$

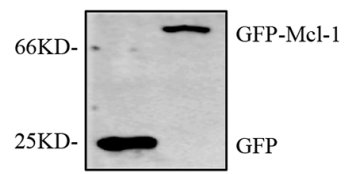

$\mathrm{F}$

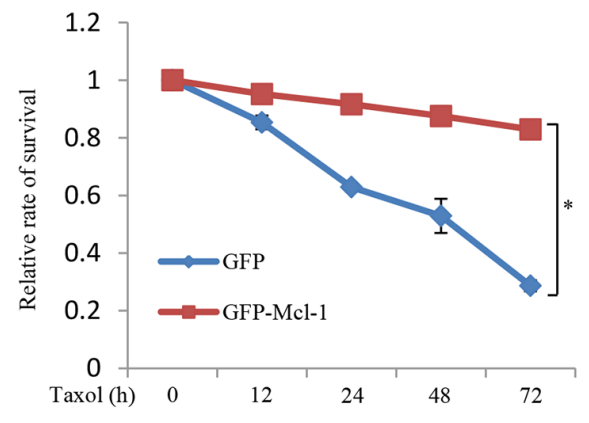

b

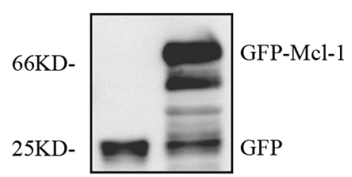

Figure 1: Mcl-1 was identified as a Taxol-resistance associated gene in gastric cancer cell. (A) MGC-803 and MGC-803R cells were treated with $100 \mathrm{nM}$ Taxol for the indicated periods of time. Viability of cells was determined by the MTT assays. (B) Long-term colony formation assay of MGC-803 and MGC-803R cells. Cells were cultured with and without $100 \mathrm{nM}$ Taxol for 3 weeks. Then all dishes were fixed, stained and photographed, Scale bar, $1 \mathrm{~cm}$. (a) and the relative colonyarea was analyzed by image J software (b). (C) Proein level of Mcl-1 in MGC-803 and MGC-803R cells was analyzed by western blot analysis. (D) MGC-803R cells stably expressing the control shRNA, Mcl-1 shRNA1 or Mcl-1 shRNA 2 were treated with $100 \mathrm{nM}$ Taxol for the indicated periods of time, then the cell viability was examined by the MTT assays (a) and the shRNA-mediated Mcl-1 knockdown was confirmed by western blot analysis (b). (E) MGC-803R cells with Mcl-1 stably knockdown were transfected with either GFP or GFP-Mcl-1. After transfection, cells were treated with $100 \mathrm{nM}$ Taxol for the indicated periods of time and then the cell viability was examined by the MTT assay. (F) MGC-803 cells stably expressing GFP or GFP-Mcl-1 were treated with $100 \mathrm{nM}$ Taxol for the indicated periods of time. Then cell viability was determined by the MTT assay (a) and the expression of GFP and GFP-Mcl-1 were confirmed by western blot analysis (b). 

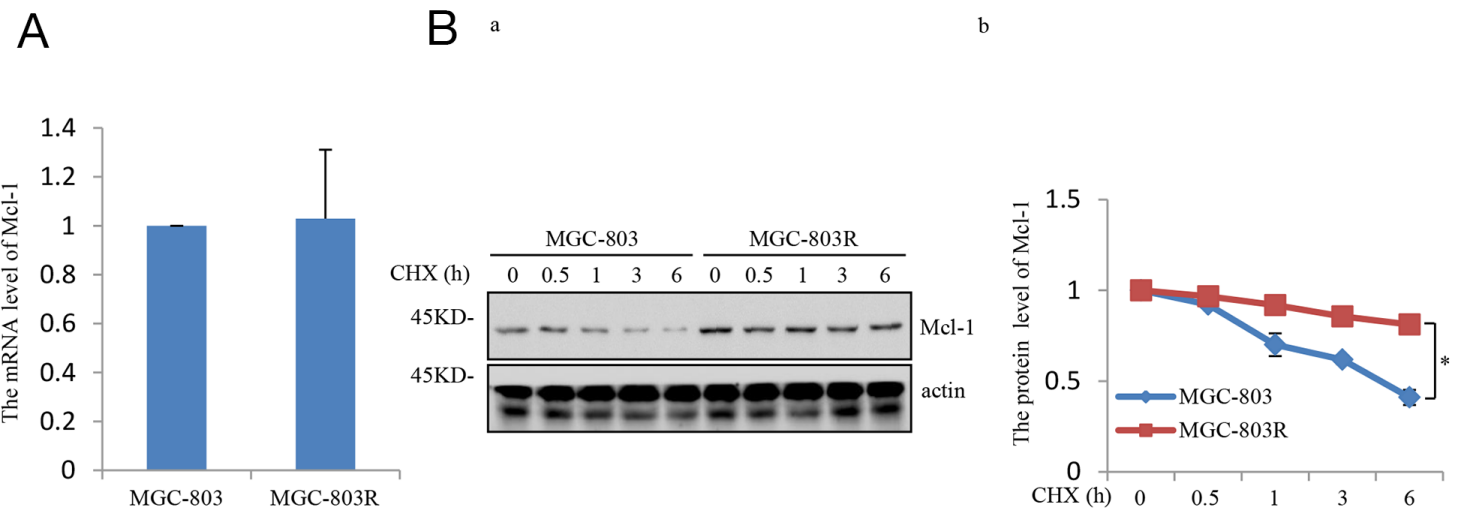

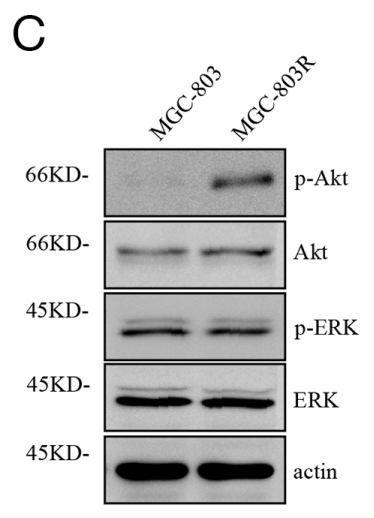

E

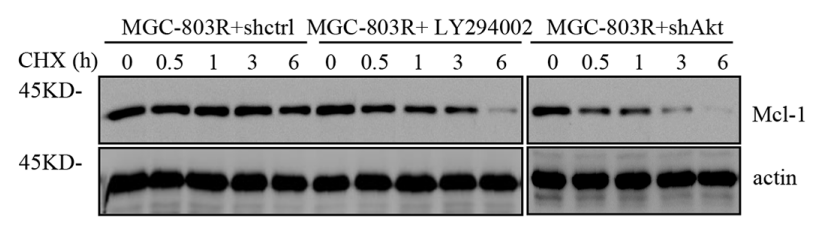

b

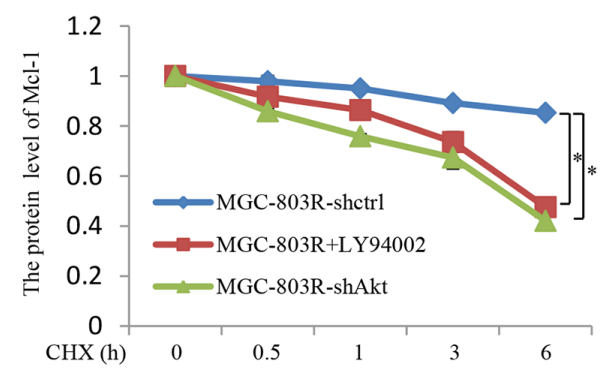

$\mathrm{D}$

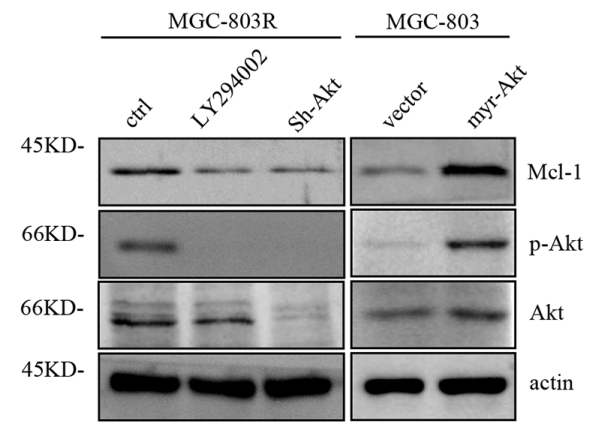

F

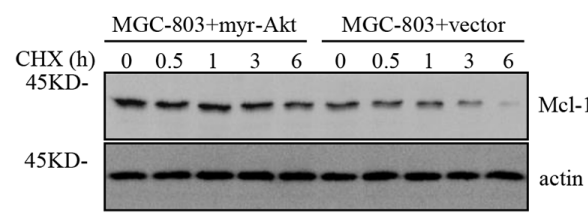

b

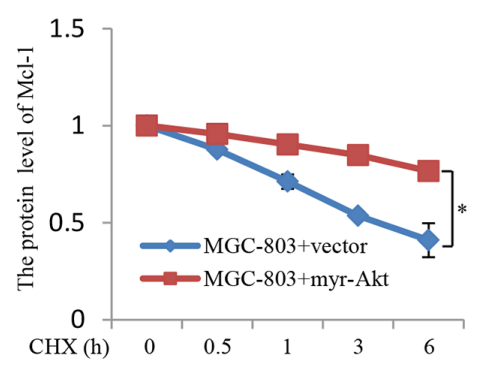

Figure 2: Mcl-1 stabilized responses to PI3K/AKT pathway hyper-activation. (A) mRNA levels of Mcl-1 in MGC-803 and MGC803R cells were analyzed by qRT-PCR. (B) MGC-803 and MGC-803R cells were treated with cycloheximide (CHX) for the indicated periods of time. Then the cell lysates were analyzed by western blot analysis with the indicated antibodies (a) and the level of Mcl-1 was quantified by Image J (b). (C) Lysates from MGC-803 and MGC-803R cells were subjected to western blot analysis with the indicated antibidies. (D) MGC-803R cells stably expressing shRNA-ctrl or shRNA-AKT or treated with LY294002 for 12 hours together with MGC-803 cells with and without myr-AKT overexpression. Then cell lysates were subjected to western blot analysis with the indicated antibodies. (E) MGC-803R cells with and without AKT stably knockdown together with MGC-803R cells treated with LY294002 for 12 hours were treated with cycloheximide for the indicated periods of time. Cell lysates then were analyzed by western blot analysis (a) and the level of Mcl-1 was quantified by Image $\mathrm{J}$ (b). (F) MGC-803 cells expressing myr-AKT or vector control were treated with cycloheximide for the indicated times and then cell lysates were evaluated by western blot analysis with the indicated antibodies (a) and the level of Mcl-1 was quantified (b). 
To further determine the role of the PI3K/Akt pathway in mediating Mcl-1 upregulation, MGC-803R cells were treated with LY294002, a specific inhibitor of PI3K, or shAkt respectively, which inhibits the PI3K/ Akt pathway. As shown in Figure 2D and Supplementary Figure 1, LY294002 or shAkt treatment led to a dramatic decrease in Mcl-1 protein level. More importantly, ectopic expression of the constitutively active form of AKT (MyrAKT) in MGC-803 cells led to a strong increase in Mcl1. We also found that the LY294002 or shAkt treatment reduced the Mcl-1 stability in MGC-803R cells and Mcl-1 half-life was increased in MGC-803 cells with Myr-Akt ectopic expression (Figure 2E and 2F). Together, these data demonstrate that Mcl-1 is stabilized by the PI3K/Akt pathway, through which Mcl-1 contributes to the acquired resistance of human gastric cancer cells to Taxol.

\section{Inhibition of PI3K/Akt pathway renders gastric cells sensitive to Taxol-induced apoptosis}

We next studied the effect of inhibition of the PI3K/ Akt pathway on Taxol-induced apoptosis in Taxol-resistant human gastric cells. More importantly, MGC-803R cells pre-treated with LY294002 or shAkt showed a dramatic decrease in cell viability in response to Taxol treatment (Figure 3A). Photos (Hoechst 33342 fluorescence) documenting the apoptosis was displayed in Figure 3B. Accordingly, MGC-803R cells exhibited high levels of caspase-3 activation and poly(ADP-ribose) polymerase (PARP) cleavage compared with control cells responsive to Taxol treatment under Akt knockdown or PI3K/Akt pathway inhibition (Figure 3C).

We also evaluated the effect of PI3K/Akt pathway on Taxol-induced inhibition on cell viability in MGC-803 cells. As shown in Figure 3D, the inhibitory effect of Taxol on cell viability was greatly reversed by ectopic expression of Myr-Akt in MGC-803 cells. Correlated with this, MyrAkt overexpression resulted in a great decrease in aberrant nuclei stained by Hoechst 33342 (Figure 3E) and a great decrease in Taxol-induced caspase- 3 activation and PARP cleavage (Figure $3 \mathrm{~F}$ ). Take together, these results point out that inhibition of PI3K/Akt pathway can render Taxolresistant gastric cells sensitive to Taxol-induced apoptosis.

\section{Inhibiting PI3K/Akt-Mcl-1 axis sensitize gastric cell to Taxol-induced apoptosis is associated with cytochrome $\mathrm{C}$ release}

Next, we explored how PI3K/Akt-Mcl-1 axis contributes to acquired resistance to Taxol in human gastric cells. Mcl-1 has been recognized as an antiapoptotic regulator of apoptosis by directly or indirectly decrease of the release of the apoptogenic proteins, like cytochrome C [16]. We therefore asked whether PI3K/ Akt-Mcl-1 axis could prevent the permeabilization of the outer mitochondria membrane and thus confers resistance to Taxol. Consistent with the previous report, knockdown Mcl-1 indeed cause an increase of the cytosolic expression of cytochrome C in MGC-803R cells upon to Taxol treatment. Furthermore, LY294002 or shAkt treatment which reduces the Mcl-1 expression also induced a dramatic increase of the cytosolic proportion of cytochrome $\mathrm{C}$ (Figure 4A and 4B). In contrast, ectopic expression of Myr-Akt in MGC-803 cells markedly inhibited the cytosolic expression of cytochrome $\mathrm{C}$ under Taxol treatment (Figure 4C and 4D). Therefore, sensitization of resistant gastric cells to Taxol-induced apoptosis by inhibition of $\mathrm{PI} 3 \mathrm{~K} / \mathrm{Akt}-\mathrm{Mcl}-1$ axis is associated with induction of cytochrome $\mathrm{C}$ release.

\section{DISCUSSION}

Chemotherapy for tumor kills target cells primarily by inducing apoptosis. Taxol was obtained from the extract of plant and exhibits potent pro-apoptotic ability in various human malignancies, including gastric cancer. Multiple studies have proved that patients with gastric cancer respond initially to Taxol treatment. Nevertheless, the therapeutic effect of Taxol in treating gastric cancer was limited by the acquired resistance in the majority of patients $[17,18]$.

Therefore, exploration of the detailed molecular mechanisms of Taxol acquired resistance remains warranted. This would facilitate the development of new therapies and identify novel biomarkers for predicting resistance. In this study, we have provided evidence that increased level of $\mathrm{Mcl}-1$ responses to $\mathrm{PI} 3 \mathrm{~K} / \mathrm{AKT}$ hyper-activation contributes to the development of Taxol acquired resistance.

Mcl-1 is a Bcl-2 family protein and was originally identified as an early induction gene from human myeloid leukemia cell line ML-1 [19]. Subsequent functional studies have shown that Mcl-1 acts as an anti-apoptotic protein and is capable of inhibiting apoptosis induced by various apoptotic stimuli, including etopside, UV irradiation, etc. [20]. Anti-apoptotic protein Mcl-1 protects mitochondrial integrity, thus blocking the release of apoptogenic proteins such as cytochrome C, Smac/ DIABLO, and AIF from the mitochondria [16, 21, 22]. More importantly, knockdown of Mcl-1 showed that the anti-apoptotic function of Mcl-1 is essential for maintenance of cell viability [23, 24]. And up-regulation of Mcl-1 is critical for survival of human melanoma cells upon endoplasmic reticulum stress [25]. Although enormous evidences suggest that Mcl-1 be involved in various cellular events, very little is known about the critical function of Mcl-1 in Taxol acquired resistance. Our study therefore uncovers a novel and unexpected function of Mcl-1 in association with Taxol resistance.

In this study, we also provide the detailed mechanism by which Mcl-1 confers acquired resistance to Taxol. Mcl1 is a short-lived protein with a quick turnover rate due 
A

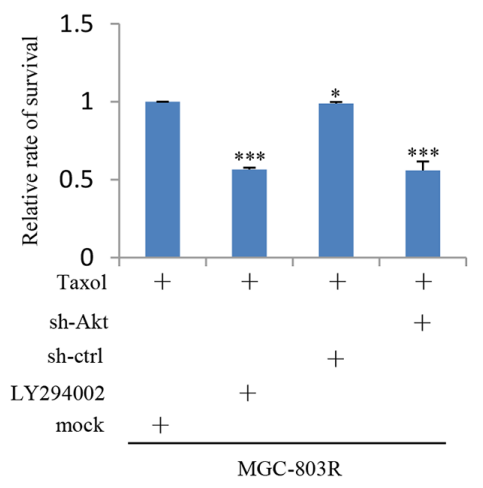

B
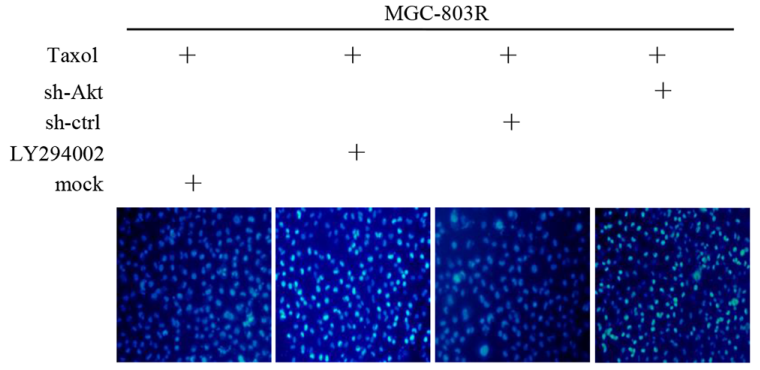
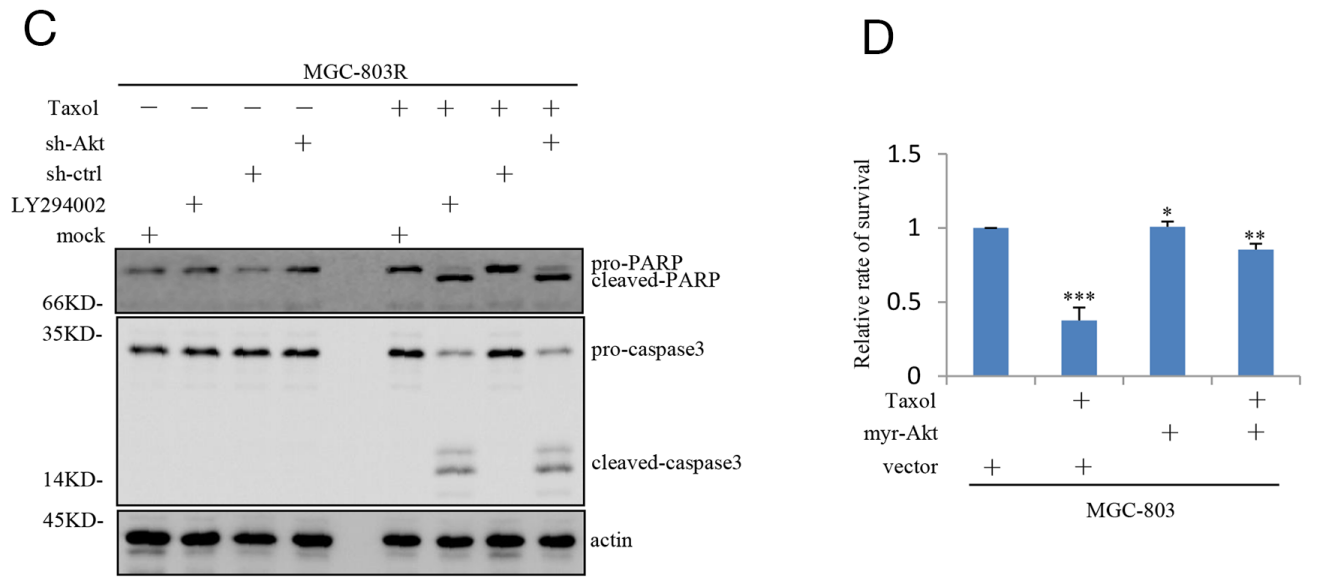

$E$

$\mathrm{F}$
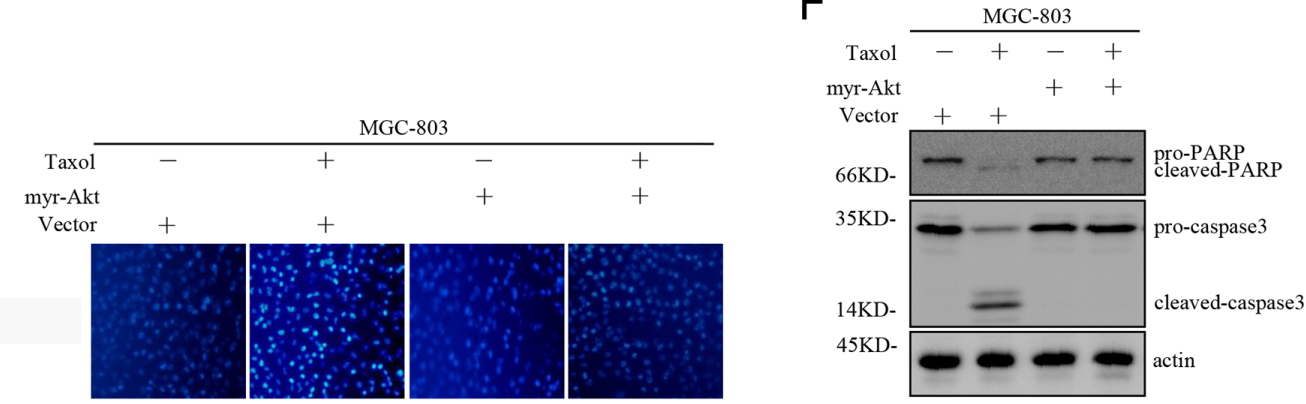

Figure 3: Inhibition of PI3K/AKT pathway attenuates the Taxol-resistance of gastric cells. (A) MGC-803R cells pre-treated with and without LY294002 for 12 hours together with MGC-803R cells stably expressing shRNA-ctrl or shRNA-AKT were treated with $100 \mathrm{nM}$ Taxol for another 48 hours. Then the cell viability was evaluated by MTT analysis. (B) MGC-803R cells pre-treated with LY294002 for 12 hours or stably knockdown AKT were treated with $100 \mathrm{nM}$ Taxol for another 48 hours. Then the cells were stained by Hoechst33342. (C) MGC-803R cells pre-treated with LY294002 or stably knockdown AKT were treated with and without $100 \mathrm{nM}$ Taxol for another 48 hours. The cell lysates were then subjected to western blot analysis with the indicated antibidies. (D) MGC-803 cells expressing myr-AKT or vector control were treated with and without $100 \mathrm{nM}$ Taxol for another 48 hours. Then the cell viability was determined by MTT analysis. (E) MGC-803 cells with and without myr-AKT overexpression were treated with $100 \mathrm{nM}$ Taxol for another 48 hours. The cells were then stained by Hoechst33342. (F) MGC-803 cells expressing myr-AKT or vector control were treated with $100 \mathrm{nM}$ Taxol for another 48 hours. Then the cell lysates were subjected to western blot analysis with the indicated antibidies. 


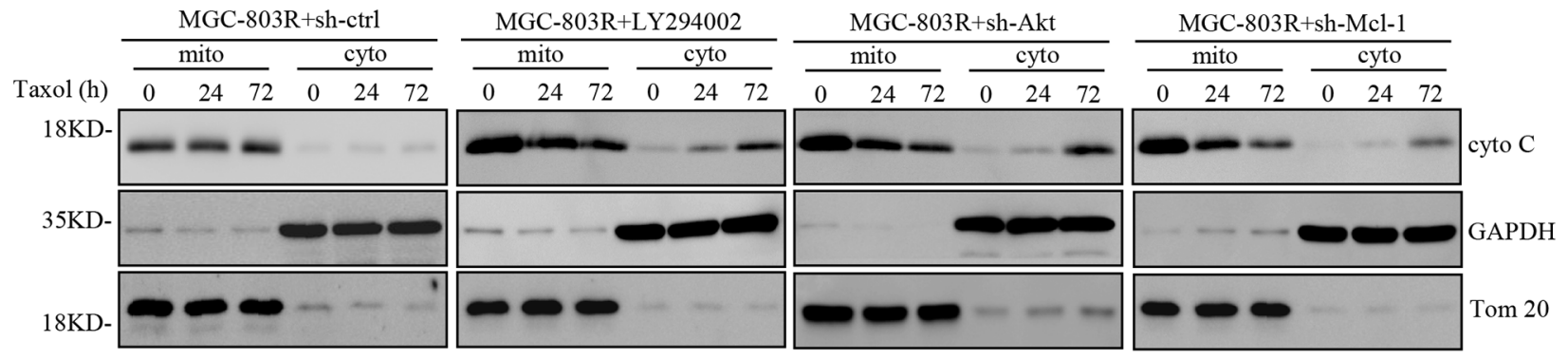

B

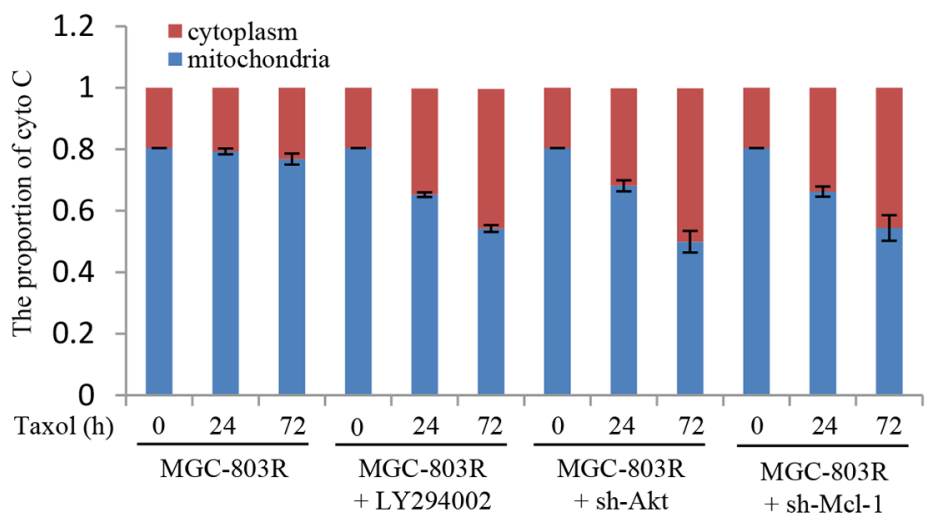

C

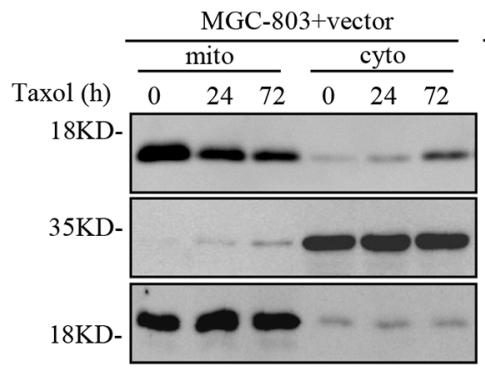

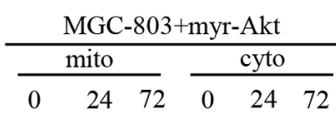

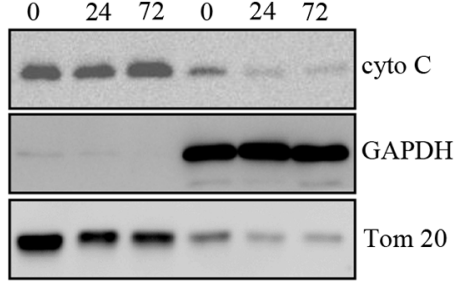

$\mathrm{D}$

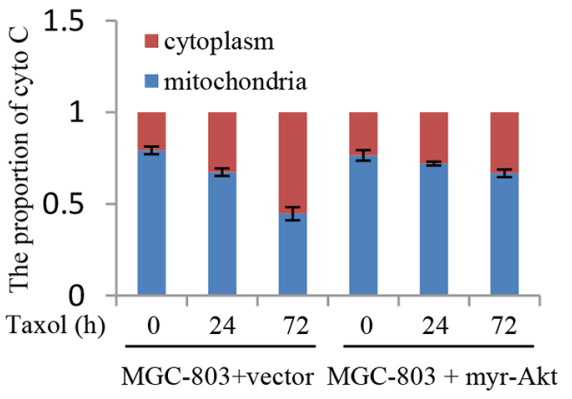

Figure 4: Sensitizes gastric cells to Taxol-induced apoptosis is associated with induction of mitochondrial membrane permeabilization. (A-B) MGC-803R cells expressing shRNA-AKT, shRNA-Mcl-1 or shRNA-ctrl together with MGC-803R cells pretreated with LY294002 for 12 hours were treated with $100 \mathrm{nM}$ Taxol for the indicated periods of time. The mitochondrial (mito) and cytoplasmic (cyto) cytochrome $\mathrm{C}$ were then isolated and subjected to western blot analysis (A) and the distribution of cytochrome $\mathrm{C}$ in mitochondria and cytoplasm was quantified by Image J (B). (C-D) MGC-803 cells with and without myr-AKT overexpression were treated with $100 \mathrm{nM}$ Taxol for the indicated periods of time. Then the mitochondrial (mito) and cytoplasmic (cyto) cytochrome $\mathrm{C}$ were isolated and subjected to western blot analysis with indicated antibodies (C) and the distribution of cytochrome $\mathrm{C}$ in mitochondria and cytoplasm was analyzed by Image J (D). 
to it contains a PEST (proline, glutamic acid, serine, and threonine) sequence in its Nterminal region [26]. So the posttranslational modification is important to maintain cellular protein level of Mcl-1. Mcl-1 is shown to be stabilized responses to PI3K/Akt pathway hyper-activation, thereby confers resistance to Taxol in human gastric cancer cells.

Akt, also referred to as PKB, is activated by various growth and survival factors to function in a pathway involving PI3 kinase [27, 28]. Activated Akt modulates the function of numerous targets involved in the regulation of cell survival and cellular growth. In recent years, it has been shown that the PI3K/Akt pathway is frequently altered in human cancers. Hyper-activated PI3K/Akt pathway mediated the survival of tumor cells and it may decisively contribute to the resistant phenotype [29]. But how PI3K/Akt pathway regulates the Taxol acquired resistance is not fully understood.

As mentioned earlier, several mechanisms of Taxolresistance have been proposed. In this study, we also validated the effect on knockdown of Taxol-resistance associated genes that have been proposed before, such as TNFAIP1 [30], GBP1 [31] and LIN28 [32]. As shown in Supplementary Figure 3, knockdown of these genes did not significantly alter sensitivity of MGC-803R cells to Taxol-induced apoptosis. These data indicate that upregulation of Mcl-1 represents a unique mechanism of acquired resistance to Taxol.

Taken together, we present an anti-apoptosis mechanism downstream of PI3K/Akt and demonstrate that stabilization of $\mathrm{Mcl}-1$ is a vital consequence of hyperactivation of the PI3K/Akt pathway. Further, we find that the enhanced Mcl-1 prevents of the permeabilization of the outer mitochondrial membrane, and identifies Mcl1 as a potential therapeutic target for the treatment of Taxol-resistant human gastric cancer. Inhibition of Mcl-1 or PI3K/Akt pathway significantly reversed the resistant phenotype of Taxol-resistant human gastric cancer cells.

\section{MATERIALS AND METHODS}

\section{Cell culture and reagents}

HEK293T and MGC803 cells were maintained in DMEM containing 10\% fetal bovine serum (FBS) and $1 \%$ penicillin-streptomycin. All cells were cultured in a humidified incubator at $37^{\circ} \mathrm{C}$ and $5 \% \mathrm{CO} 2$. Taxol (T7191) and Cycloheximide (c4859) were obtained from Sigma, Taxol was dissolved in DMSO to make up stock solutions of $50 \mathrm{mg} / \mathrm{ml}$. LY294002 (S1737), UO126 (S1901) and Hoechst33342 (C1026) were purchased from Beyotime.

\section{Generation of taxol-resistant human gastric cancer cell line}

MGC-803 cells were treated with $50 \mathrm{nM}$ Taxol for about 5 days, Then the remaining live cells were transferred to the culture medium containing $50 \mathrm{nM}$ Taxol for at least 4 weeks before they were used for the subsequent studies.

\section{Cytosolic and mitochondrial subcellular fractionation}

Cytosolic and mitochondrial subcellular fractionation was carried out as described previously [33]. Briefly, cells were homogenized in homogenization buffer (20 mM HEPES-KOH, pH 7.5, 1.5 mM MgCl2, $10 \mathrm{mM} \mathrm{KCl}, 1 \mathrm{mM}$ sodium EGTA, $1 \mathrm{mM}$ sodium EDTA, $1 \mathrm{mM}$ dithiothreitol, $250 \mathrm{mM}$ sucrose and protease inhibitor cocktail). The homogenates were subjected to centrifugation at $600 \mathrm{~g}$ for $5 \mathrm{~min}$ at $4^{\circ} \mathrm{C}$. The supernatant fraction was collected and centrifuged again at $7000 \mathrm{~g}$ for $10 \mathrm{~min}$ at $4^{\circ} \mathrm{C}$ to obtain cytoplasmic and mitochondrial fractions. The mitochondrial pellet was washed and solubilized in TNC buffer (10 mM Tris acetate, $\mathrm{pH} 8.0$, $5 \mathrm{mM} \mathrm{CaCl} 2,0.5 \% \mathrm{NP}-40$ and cocktail). The protein concentration was determined with a BCA kit before western bot analysis.

\section{Western blot analysis}

Western blot analysis was performed as described previously [34]. The following antibodies were used in this study: anti-AKT (Cell Signaling, 2920S), antiphospho-ERK(CellSignaling,4370S), anti-phosphoAKT(Ser473) (Epitomics,2118-1), anti-GAPDH(Santa Cruz Biotechnology, SC-32233), PARP(Santa Cruz Biotechnology, SC-8007), anti-caspase-3(Cell Signaling, 9665S), anti-actin(Sigma, A4700), anticytochrome C(Santa Cruz Biotechnology, SC-13156), anti-Tom20(Santa Cruz Biotechnology, SC-136211), anti-Mcl-1(Santa Cruz Biotechnology, SC-819), anti-GFP(Sigma, G1544), anti-ERK(Cell Signaling, 4695S), anti-TNFAIP1(proteintech, 60327), antiLIN28(proteintech,11724), anti-GBP1(proteintech, 15303), anti-Bcl-2(proteintech, 12789), anti-Bxlxl(proteintech, 26967), anti-GSK3 $\alpha($ Cell Signaling, 9338), anti-phospho-GSK3 $\alpha(\operatorname{ser} 21)($ Boster, P03152), anti-GSK3 $\beta$ (Cell Signaling, 12456), anti-phosphoGSK3 $\beta$ (ser9)( Cell Signaling, 5558).

\section{RNA isolation and qRT-PCR}

Total RNA was isolated using Trizol reagent (Invitrogen). The assay was performed as previously described [35]. The following primers were used in this study for Mcl-1: F: 5'-GCCAAGGACACAAAGCCAAT-3', R: 5'-AACTCCACAAACCCATCCCA-3'

\section{Colony formation assay}

MGC803 and MGC803R cells were plated at a density of 3000 cells per well on a six-well plate and were 
incubated with and without $50 \mathrm{nM}$ Taxol for 3 weeks. Then cells were washed with PBS and fixed with 70\% cold methanol for $15 \mathrm{~min}$, followed by staining with $0.005 \%$ $(\mathrm{m} / \mathrm{v})$ crystal violet for $30 \mathrm{~min}$ at room temperature. After gentle wash, the colonies were photographed.

\section{MTT assay}

Cells were seeded in 96-well plates and treated with and without Taxol for the indicated times. 20ul of $5 \mathrm{mg} /$ $\mathrm{ml}$ MTT solution was added to each well followed by incubation at $37^{\circ} \mathrm{C}$ for $4 \mathrm{~h}$. Then cells were incubated with DMSO for additional $10 \mathrm{~min}$ at $37^{\circ} \mathrm{C}$. The absorbance at $570 \mathrm{~nm}$ was detected by a microplate reader.

\section{Hoechst 33342 staining}

MGC803 and MGC803R cells were plated at a density of 15000 cells per well on a 24-well plate, followed with the indicated treatments. The viability of cells was evaluated by counting apoptotic cells characteristic of aberrant nuclei staining by Hoechst 33342 .

\section{Lentivirus package and RNA interference}

Lentiviral plasmids PLKO.1 and PLKO.1-shMcl-1 or PLKO.1-shAkt were co-transfected with pREV, pGag/ Pol and pVSVG into HEK293T cells using Lipo3000. Viral supernatant was collected $48 \mathrm{~h}$ post transfection, filtered and added to cells in the presence of $8 \mu \mathrm{g} / \mathrm{ml}$ polybrene. The transduced cells were selected by $0.5 \mu \mathrm{g} / \mathrm{ml}$ puromycin. Followed are sequences used to knockdown Mcl-1: 5'- GCTGTGTTAAACCTCAGAGTT-3' and 5'GCAGAAAGTATCACAGACGTT-3'; Akt: 5'- GCAT CGCTTCTTTGCCGGTAT-3' and 5'- CGCGTGACCA TGAACGAGTTT-3'; TNFAIP1: 5'- CCCATGTCTTTC TACCCTAAT-3' and 5'- GCTGCTGTACAACAGA AGCAA-3'; LIN28: 5'- GCACCAGAGTAAG CTGCACAT-3' and 5'- ACCTACTTTCGAG AGGAAGAA-3'; GBP1: 5'- CCTCTGTATCAACT CAGGAAA-3' and 5' ${ }^{\prime}$ CGGAAATTCTTCC CAAAGAAA-3'.

\section{Statistical analysis}

Statistical analysis was carried out using Microsoft Excel software. Statistical significance was analyzed by Student's t test and expressed as a $p$ value. $p$ values lower than 0.05 were considered to be statistical significance.* and $* *$ indicate $\mathrm{p}<0.05$ and $\mathrm{p}<0.01$, respectively.

\section{ACKNOWLEDGMENTS}

The author thanks Prof. Yan Ye (Anhui Medical University) for gastric cancer cell line MGC-803. This work was supported by grants from National
Natural Science Foundation of China (31601117) and Natural Science Foundation of Anhui Provice (1508085QH181).

\section{CONFLICTS OF INTEREST}

The authors declare no conflicts of interest.

\section{REFERENCES}

1. Zha Y, Gan P, Liu Q, Yao Q. TP53 codon 72 polymorphism predicts efficacy of paclitaxel plus capecitabine chemotherapy in advanced gastric cancer patients. Arch Med Res. 2016; 47:13-18.

2. Jin B, Liu YP, Wang HJ. Antagonism of miRNA-21 sensitizes human gastric cancer cells to paclitaxel. Cell Biochem Biophys. 2015; 72:275-282.

3. Wang SQ, Wang C, Chang LM, Zhou KR, Wang JW, Ke Y, Yang DX, Shi HG, Wang R, Shi XL, Ma LY, Liu HM. Geridonin and paclitaxel act synergistically to inhibit the proliferation of gastric cancer cells through ROSmediated regulation of the PTEN/PI3K/Akt pathway. Oncotarget. 2016; 7:72990-73002. https://doi.org/10.18632/ oncotarget.12166.

4. Wang C, Wang R, Zhou KR, Wang SQ, Wang JW, Shi HG, Dou YH, Yang DX, Chang LM, Shi XL, Liu Y, Xu XW, Zhang XJ, et al. JD enhances the anti-tumour effects of low-dose paclitaxel on gastric cancer MKN45 cells both in vitro and in vivo. Cancer Chemother Pharmacol. 2016; 78:971-982.

5. Monzo M, Rosell R, Sanchez JJ, Lee JS, O'Brate A, Gonzalez-Larriba JL, Alberola V, Lorenzo JC, Nunez L, Ro JY, Martin C. Paclitaxel resistance in non-small-cell lung cancer associated with beta-tubulin gene mutations. J Clin Oncol. 1999; 17:1786-1793.

6. Sakamoto J, Matsui T, Kodera Y. Paclitaxel chemotherapy for the treatment of gastric cancer. Gastric Cancer. 2009; 12:69-78.

7. Dumontet C, Sikic BI. Mechanisms of action of and resistance to antitubulin agents: microtubule dynamics, drug transport, and cell death. J Clin Oncol. 1999; 17:1061-1070.

8. Horwitz SB, Cohen D, Rao S. Taxol: mechanisms of action and resistance. J Natl Cancer Inst. 1993;15:55-61.

9. Scatena CD, Stewart ZA, Mays D, Tang LJ, Keefer CJ, Leach SD, Pietenpol JA. Mitotic phosphorylation of Bcl-2 during normal cell cycle progression and taxol-induced growth arrest. J Biol Chem. 1998; 273:30777-30784.

10. Hu J, Zhang N, Wang RL, Huang F, Li G. Paclitaxel induces apoptosis and reduces proliferation by targeting epidermal growth factor receptor signaling pathway in oral cavity squamous cell carcinoma. Oncol Lett. 2015; 10:2378-2384. 
11. Bocci G, Di Paolo A, Danesi R. The pharmacological bases of the antiangiogenic activity of paclitaxel. Angiogenesis. 2013; 16:481-492.

12. Jin H, Park MH, Kim SM. 3,3'-Diindolylmethane potentiates paclitaxel-induced antitumor effects on gastric cancer cells through the Akt/FOXM1 signaling cascade. Oncol Rep. 2015; 33:2031-2036.

13. Jeong JY, Kim KS, Moon JS, Song JA, Choi SH, Kim KI, Kim TH, An HJ. Targeted inhibition of phosphatidyl inositol-3-kinase p110 beta, but not p110 alpha, enhances apoptosis and sensitivity to paclitaxel in chemoresistant ovarian cancers. Apoptosis. 2013; 18:509-520.

14. Jin L, Hu WL, Jiang CC, Wang JX, Han CC, Chu P, Zhang LJ, Thorne RF, Wilmott J, Scolyer RA, Hersey P, Zhang XD, Wu M. MicroRNA-149*, a p53-responsive microRNA, functions as an oncogenic regulator in human melanoma. Proc Natl Acad Sci U S A. 2011; 108:15840-15845.

15. Maurer U, Charvet C, Wagman AS, Dejardin E, Green DR. Glycogen synthase kinase-3 regulates mitochondrial outer membrane permeabilization and apoptosis by destabilization of MCL-1. Mol Cell. 2006; 21:749-760.

16. Martinou JC, Green DR. Breaking the mitochondrial barrier. Nat Rev Mol Cell Bio. 2001; 2:63-67.

17. Almhanna K, Cubitt CL, Zhang SM, Kazim S, Husain K, Sullivan D, Sebti S, Malafa M. MK-2206, an Akt inhibitor, enhances carboplatinum/paclitaxel efficacy in gastric cancer cell lines. Cancer Biol Ther. 2013; 14:932-936.

18. Satoh T, Xu RH, Chung HC, Sun GP, Doi T, Xu JM, Tsuji A, Omuro Y, Li J, Wang JW, Miwa H, Qin SK, Chung IJ, et al. Lapatinib plus paclitaxel versus paclitaxel alone in the second-line treatment of HER2-amplified advanced gastric cancer in Asian populations: TyTANA- a randomized, phase III study. J Clin Oncol. 2014; 32:2039-U2089.

19. Kozopas KM, Yang T, Buchan HL, Zhou P, Craig RW. Mcl1, a gene expressed in programmed myeloid celldifferentiation, has sequence similarity to Bcl2. Proc Natl Acad Sci U S A. 1993; 90:3516-3520.

20. Zhou P, Qian LP, Kozopas KM, Craig RW. Mcl-1, a Bcl-2 family member, delays the death of hematopoietic cells under a variety of apoptosis-inducing conditions. Blood. 1997; 89:630-643.

21. Adams JM, Cory S. The Bcl-2 protein family: arbiters of cell survival. Science. 1998; 281:1322-1326.

22. Wang YF, Jiang CC, Kiejda KA, Gillespie S, Zhang XD, Hersey P. Apoptosis induction in human melanoma cells by inhibition of MEK is caspase-independent and mediated by the Bcl-2 family members PUMA, Bim, and Mcl-1. Clin Cancer Res. 2007; 13:4934-4942.

23. Moulding DA, Giles RV, Spiller DG, White MR, Tidd DM, Edwards SW. Apoptosis is rapidly triggered by antisense depletion of MCL-1 in differentiating U937 cells. Blood. 2000; 96:1756-1763.
24. Nijhawan D, Fang M, Traer E, Zhong Q, Gao WH, Du $\mathrm{FH}$, Wang XD. Elimination of Mcl-1 is required for the initiation of apoptosis following ultraviolet irradiation. Genes Dev. 2003; 17:1475-1486.

25. Jiang CC, Lucas K, Avery-Kiejda KA, Wade M, deBock CE, Thorne RF, Allen J, Hersey P, Zhang XD. Up-regulation of Mcl-1 is critical for survival of human melanoma cells upon endoplasmic reticulum stress. Cancer Res. 2008; 68:6708-6717.

26. Rogers S, Wells R, Rechsteiner M. Amino-acid-sequences common to rapidly degraded proteins - the pest hypothesis. Science. 1986; 234:364-368.

27. Burgering BM, Coffer PJ. Protein-kinase-B (C-Akt) in phosphatidylinositol-3-Oh inase signal-transduction. Nature. 1995; 376:599-602.

28. Franke TF, Yang SI, Chan TO, Datta K, Kazlauskas A, Morrison DK, Kaplan DR, Tsichlis PN. The proteinkinase encoded by the Akt protooncogene is a target of the Pdgf-activated phosphatidylinositol 3-kinase. Cell. 1995; 81:727-736.

29. Vara JA, Casado E, de Castro J, Cejas P, Belda-Iniesta C, Gonzalez-Baron M. PI3K/Akt signalling pathway and cancer. Cancer Treat Rev. 2004; 30:193-204.

30. Zhu Y, Yao Z, Wu Z, Mei Y, Wu M. Role of tumor necrosis factor alpha-induced protein 1 in paclitaxel resistance. Oncogene. 2014; 33:3246-3255.

31. Duan ZF, Foster R, Brakora KA, Yusuf RZ, Seiden MV. GBP1 overexpression is associated with a paclitaxel resistance phenotype. Cancer Chemother Pharmacol. 2006; 57:25-33.

32. Lv K, Liu L, Wang L, Yu J, Liu X, Cheng Y, Dong M, Teng R, Wu L, Fu P, Deng W, Hu W, Teng L. Lin28 mediates paclitaxel resistance by modulating $\mathrm{p} 21, \mathrm{Rb}$ and Let- $7 \mathrm{a}$ miRNA in breast cancer cells. PLoS One. 2012; 7:e40008.

33. Cheng B, Xu A, Qiao MR, Wu Q, Wang WY, Mei YD, Wu MA. BECN1s, a short splice variant of BECN1, functions in mitophagy. Autophagy. 2015; 11:2048-2056.

34. Li Q, Zhu Y, Hou L, Wang J, Hu G, Fang X, Hu Y, Tao T, Wei X, Tang H, Huang B, Hu W. C23 promotes tumorigenesis via suppressing p53 activity. Oncotarget. 2016; 7:58274-58285. https://doi.org/10.18632/ oncotarget.11071.

35. Hu W, Jin L, Jiang C, Long G, Scolyer R, Wu Q, Zhang $\mathrm{X}$, Mei Y, Wu M. AEBP1 upregulation confers acquired resistance to BRAF (V600E) inhibition in melanoma. Cell Death Dis. 2013; 4:e914. 